\title{
TEMPERATURA DO AR, RENDIMENTO DE GRÃOS DE MILHO E CARACTERIZAÇÃO FENOLÓGICA ASSOCIADAÀ SOMA CALÓRICA ${ }^{1}$
}

\author{
João Luiz Gadioli ${ }^{2,4,5}$; Durval Dourado-Neto ${ }^{3,6 *}$; Axel García y García ${ }^{3,6}$; Maria del Valle Basanta² \\ ${ }^{2}$ Pós-Graduando do Depto. de Produção Vegetal - USP/ESALQ. \\ ${ }^{3}$ Depto. de Produção Vegetal - USP/ESALQ, C.P. 9 - CEP: 13418-970 - Piracicaba, SP. \\ ${ }_{5}^{4}$ Depto. de Ciências Agrárias - UNITAU, C.P. 227 - CEP: 12010-970 - Taubaté, SP. \\ ${ }^{5}$ Bolsista CAPES. \\ ${ }^{6}$ Bolsista CNPq. \\ *Autor correspondente <dourado@carpa.ciagri.usp.br>
}

\begin{abstract}
RESUMO: Com os objetivos de avaliar o efeito da temperatura média do ar no rendimento de grãos e de prever a época de ocorrência dos estádios fenológicos da cultura de milho em função da soma calórica, foi conduzido um experimento de campo utilizando três híbridos, com diferentes exigências térmicas, em três diferentes épocas de semeadura. Para estimativa do rendimento de grãos foram determinados seus diferentes componentes, onde se observou um decréscimo do rendimento com aumento da temperatura em função das épocas de semeadura utilizadas. A fenologia foi associada ao número relativo de graus-dia, onde se observou uma relação linear. Há uma temperatura média do ar correspondente ao máximo rendimento de grãos, e os estádios fenológicos da cultura podem ser previstos através do conhecimento prévio da série histórica de temperatura da localidade e da soma calórica requerida para o ponto de maturidade fisiológica.
\end{abstract}

Palavras-chave: milho, fenologia, graus-dia

\section{AIR TEMPERATURE, MAIZE YIELD AND PHENOLOGICAL CHARACTERIZATION ASSOCIATED TO HEAT UNITS}

\begin{abstract}
With the purpose of evaluating the effect of the mean daily air temperature on grain yield and to predict the occurrence of the maize crop phenological phases as function of heat units, a field experiment was carried out using three hybrids with different heat unit requirements and three sowing dates. To estimate grain productivity, different yield components were determinated. Crop phenology was associated to the relative degree-days, for which a linear relation was observed. There is a mean air temperature corresponding to maximum grain yield, and the crop phenological phases can be predicted knowing the local historical temperature series and the thermic index for physiological maturity.

Key words: maize, phenology, thermic index
\end{abstract}

\section{INTRODUÇÃO}

A cultura de milho no Brasil apresenta rendimentos inferiores a $3.000 \mathrm{~kg} \mathrm{ha}^{-1}$, valores abaixo do rendimento possível de ser atingido com a tecnologia atualmente disponível. Adequação do material genético em função das condições otimizam o desempenho fisiológico, minimizando custos e maximizando rendimento de grãos.

Através de evidências experimentais, a época recomendável indicada para o estabelecimento da cultura de milho é dependente da ocorrência de chuva e das condições de temperatura (não irrigado: cerca de $90 \%$ dos quase 14 milhões de hectares semeados no Brasil). Esse fato associado a uma grande disponibilidade de híbridos no mercado, resultam em épocas de semeadura que variam de região para região.

Em função dos eventos que ocorrem ao longo do ciclo da cultura, é possível estabelecer estádios de desenvolvimento caracterizados por alterações morfológicas provocadas principalmente pelo ambiente. A duração das fases fenológicas de uma cultura, avaliada pelo número de dias, varia entre regiões, anos e datas de semeadura, em razão das variações climáticas, como umidade relativa, temperatura do ar e do solo, chuva, radiação solar e fotoperíodo (Costa, 1994).

No desenvolvimento do milho, a duração do ciclo em dias tem demonstrado inconsistência. Isso se deve ao fato de que a duração de subperíodos e ciclos da planta estão associados às variações das condições ambientais e não ao número de dias. A temperatura tem-se apresentado como o elemento climático mais importante para predizer os eventos fenológicos da cultura, desde que não haja deficiência hídrica.

A utilização da temperatura média do ar, numa escala diária, é uma boa estimativa indireta da quantidade de energia química metabólica produzida pelo material genético.

O ciclo de uma cultivar de milho pode ser caracterizado em função do número de dias desde a semeadura até a maturidade fisiológica ou a colheita.

Parte da Dissertação de Mestrado do primeiro autor apresentada à USP/ESALQ - Piracicaba, SP.

Scientia Agricola, v.57, n.3, p.377-383, jul./set. 2000 
Porém o método mais satisfatório para determinar as etapas de desenvolvimento da cultura leva em consideração as exigências calóricas ou térmicas, designadas como unidades calóricas $\left({ }^{0} \mathrm{C}\right)$, unidades térmicas de desenvolvimento (U.T.D.) ou graus-dia (GD) (Fancelli \& Dourado-Neto, 1997). Estima-se a soma das unidades diárias de calor, a partir da emergência para 0 material genético atingir um determinado estádio, pela diferença entre a temperatura média diária e as temperaturas base mínima ou máxima exigidas pela espécie vegetal.

O método dos graus-dia baseia-se na premissa de que uma planta necessita de uma certa quantidade de energia, representada pela soma de graus térmicos necessários, para completar determinada fase fenológica ou mesmo o seu ciclo total. Admite, além disso, uma relação linear entre acréscimo de temperatura e desenvolvimento vegetal. Cada espécie vegetal ou variedade possui uma temperatura base, que pode variar em função da idade ou da fase fenológica da planta. É comum adotar uma única temperatura base para todo o ciclo da planta por ser mais fácil a sua aplicação (Prett, 1992).

A cultura de milho apresenta as seguintes exigências térmicas (GD), expressas em ${ }^{\circ} \mathrm{C}$.dia, para 0 florescimento: (i) híbridos tardios: GD superior a $890^{\circ} \mathrm{C}$.dia; (ii) híbridos precoces: superior a $831^{\circ} \mathrm{C}$.dia e inferior $890^{\circ} \mathrm{C}$.dia, e (iii) híbridos superprecoces: inferior a $830^{\circ} \mathrm{C}$.dia (Fancelli e Dourado-Neto, 1997). Mundstock (1970), Brunini et al. (1983), Berlato et al. (1984) e Garcia (1993) são alguns dos autores que evidenciam o efeito da temperatura no crescimento e desenvolvimento da cultura do milho.

O conhecimento das exigências térmicas, desde a emergência ao ponto de maturidade fisiológica, é fundamental para a previsão da duração do ciclo da cultura em função do ambiente. Essas informações, associadas ao conhecimento da fenologia da cultura, podem ser utilizadas no planejamento para definição da época de semeadura, da utilização de insumos (fertilizantes, inseticidas, fungicidas e herbicidas, principalmente), da época de colheita (colheita de grãos ou momento de corte de milho para silagem).
A determinação da melhor época de semeadura em função das necessidades térmicas da cultura tem sido objeto de estudo por Lima et al. (1980), Pacheco (1982), Noldin \& Mundstock (1988), Souza (1989), Oliveira (1990) e Brunini (1997), colocando em evidência a necessidade de se trabalhar, em termos de manejo, com a relação funcional entre fenologia e graus-dia.

O presente trabalho teve por objetivos avaliar o efeito da temperatura média do ar no rendimento de grãos e de prever a época de ocorrência dos estádios fenológicos da cultura de milho em função da soma calórica.

\section{MATERIAL E MÉTODOS}

O experimento foi conduzido na área experimental da Fazenda Piloto do Departamento de Ciências Agrárias, Universidade de Taubaté (UNITAU), ano agrícola 97/98, no Município de Taubaté, Estado de São Paulo. O local apresenta as coordenadas geográficas $23^{\circ} 02^{\prime} 34^{\prime \prime}$ de latitude, $45^{\circ} 31^{\prime} 02^{\prime \prime}$ de longitude e 577 metros de altitude. O solo é Gley Pouco Húmico e suas características químicas e físicas são apresentadas na TABELA 1. O clima do local, de acordo com a classificação de Köppen (1948) é do tipo Cwa, com uma precipitação média anual de $1300 \mathrm{~mm}$.

O preparo do solo foi realizado em forma convencional, com uma aração e duas gradagens. Foram aplicadas 2,5 $\mathrm{t} \mathrm{ha}^{-1}$ de calcário dolomítico (CaO: 23\%; MgO: $15 \%$; e PRNT: $70 \%$ ), aplicando-se metade da dose antes da primeira gradagem destorroadora e metade antes da segunda gradagem niveladora, as quais foram realizadas em 18 de agosto de 1997.

A adubação na semeadura foi de $600 \mathrm{~kg} \mathrm{ha}^{-1}$ de 4-14-8 misturados com $30 \mathrm{~kg} \mathrm{ha}^{-1}$ de nitrocálcio, totalizando $30 \mathrm{~kg} \mathrm{ha}^{-1}$ de N, $90 \mathrm{~kg} \mathrm{ha}^{-1}$ de $\mathrm{P}_{2} \mathrm{O}_{5}$ e $50 \mathrm{~kg} \mathrm{ha}^{-1}$ de $\mathrm{K}_{2} \mathrm{O}$, e a adubação de cobertura foi feita de acordo com a exigência da cultura (Raij et al., 1996).

Foram utilizados três híbridos de milho da Cargill²: (i) híbrido I, C901 - superprecoce (790 UC); (ii) híbrido II, C333B - normal (870 UC) e (iii) híbrido III, C806 superprecoce (810 UC); e semeados em três diferentes épocas: (i) época 1, 18 de setembro de 1997; (ii) época 2, 20 de outubro de 1997 e (iii) época 3, 9 de dezembro de 1997. A população final de plantas ha ${ }^{-1}$ foi de 60 mil para o híbrido I e de 50 mil para os híbridos II e III.

TABELA 1 - Características químicas $(0,0$ a 0,2 m) e granulometria da área experimental.

\begin{tabular}{|c|c|c|c|c|c|c|c|c|}
\hline $\begin{array}{c}\mathrm{pH} \\
\mathrm{CaCl}_{2} \\
\end{array}$ & M.O. & P-resina & $\mathrm{K}^{+}$ & $\mathrm{Ca}^{2+}$ & $\mathrm{Mg}^{2+}$ & $\mathrm{H}^{+} \mathrm{Al}^{3+}$ & $\mathrm{Cu}^{2+}$ & $\mathrm{Zn}^{2+}$ \\
\hline & $g \mathrm{dm}^{-3}$ & $\mathrm{mg} \mathrm{kg}^{-1}$ & \multicolumn{4}{|c|}{$\begin{array}{ll} & \\
\end{array}$} & \multicolumn{2}{|c|}{-------- $\mathrm{mg} \mathrm{dm}^{-3}$} \\
\hline 4,4 & 18 & 6 & 2,9 & 18 & 9 & 49 & 2,5 & 1,9 \\
\hline \multicolumn{3}{|c|}{ Areia total } & \multicolumn{2}{|c|}{ Silte } & \multicolumn{2}{|c|}{ Argila } & \multicolumn{2}{|c|}{ Classe textural } \\
\hline & 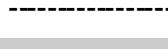 & 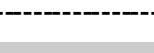 & \multicolumn{4}{|c|}{------- } & --- & --- \\
\hline & 200 & & \multicolumn{2}{|c|}{410} & \multicolumn{2}{|c|}{390} & \multicolumn{2}{|c|}{ Franco-argiloso } \\
\hline
\end{tabular}

${ }^{2}$ Características obtidas da Divisão de Sementes Híbridas da Cargill Brasil.

Scientia Agricola, v.57, n.3, p.377-383, jul./set. 2000 
Utilizaram-se 4 linhas de semeadura para cada híbrido, totalizando uma área de $864 \mathrm{~m}^{2}$ em cada época e $2.592 \mathrm{~m}^{2}$ nas três épocas. Consideraram-se as 2 linhas centrais para a coleta de dados (método destrutivo) e as 2 laterais como bordadura.

Anotou-se o momento da emergência com $50 \%$ das plântulas emergidas e fez-se a contagem do número de folhas até a abertura de todas (fase vegetativa $-50 \%$ de folhas totalmente expandidas). Selecionaram-se, durante a fase de crescimento da cultura, 3 grupos de 5 plantas para cada híbrido, objetivando determinar os estádios fenológicos, conforme metodologia utilizada por Fancelli \& Dourado-Neto (1997), em observações visuais dos estádios numa escala de 0 a 10. Para não perder 0 número de folhas, foram marcadas com barbante plástico em virtude da senescência.

$\mathrm{Na}$ colheita, foram separadas 15 espigas de cada híbrido e em cada época para a determinação do número de fileiras e o número de grãos por fileira. Após debulha manual, foram secadas até atingir $13 \%$ de umidade. Separou-se $1 \mathrm{~kg}$ de grãos e foram contadas 8 vezes grupos de 100 sementes viáveis, determinando-se o peso de cada grupo conforme preconizado no manual de sementes (Brasil, 1992).

Para a estimativa do rendimento $\left(\mathrm{R}, \mathrm{kg} \mathrm{ha}^{-1}\right)$ de grãos na cultura do milho, utilizou-se a seguinte equação:

$$
R=\frac{P \cdot \operatorname{Pr} . F e \cdot G \cdot M}{1000}
$$

em que $\mathrm{P}$ refere-se à população na colheita (plantas. ha $^{-1}$ ); $\mathrm{Pr}$ à prolificidade (espigas. planta ${ }^{-1}$ ); $\mathrm{Fe}$ ao número médio de fileiras de grãos por espiga; $G$ ao número médio de grãos por fileira; e $M$ à massa média por unidade de grão (g.grão $\left.{ }^{-1}\right)$.

Os dados de clima foram obtidos na Estação Meteorológica do Departamento de Ciências Agrárias da UNITAU, distante cerca de 800 metros da área experimental.

O número de graus-dia para o florescimento $\left(G D_{f 1}\right)$ e ponto de maturidade fisiológica $\left(G D_{\text {pmf }}\right)$ foram calculados a partir da emergência das plantas usando as equações 2, 3, 4 e 5:

$$
\begin{aligned}
& G D_{f l}=\sum_{i=1}^{N_{f}}\left[\frac{\left(T \max _{i}+T \min _{i}\right)}{2}-T b\right]\left(\text { se } T m>\operatorname{Tmax}_{\mathrm{i}} \text { e Tmin }>\right.\text { > Tb) } \\
& G D_{f l}=\sum_{i=1}^{N_{f}}\left[\frac{\left(T m+T \min _{i}\right)}{2}-T b\right]\left(\text { se } \operatorname{Tmax}_{\mathrm{i}}>\mathrm{Tm} \text { e Tmin }{ }_{\mathrm{i}}>\mathrm{Tb}\right) \\
& G D_{p m f}=\sum_{i=1}^{N_{p m p}}\left[\frac{\left(T \max _{i}+T b\right)}{2}-T b\right]\left(\text { se } T m>T \max _{i} \text { e Tb }>\operatorname{Tmin}_{(i)}\right) \\
& G D_{p m f}=\sum_{i=1}^{N_{p m p}}\left[\frac{(T m+T b)}{2}-T b\right]\left(\text { se } \operatorname{Tmax}_{\mathrm{i}}>\mathrm{Tm} \text { e Tb }>\operatorname{Tmin}_{(\mathrm{i})}\right)
\end{aligned}
$$

em que Tmax e Tmin se referem, respectivamente, às temperaturas $\left({ }^{\circ} \mathrm{C}\right)$ máxima e mínima diária do ar, e Tb e $\mathrm{Tm}$ às temperaturas basais inferior $\left(10^{\circ} \mathrm{C}\right)$ e superior $\left(30^{\circ} \mathrm{C}\right)$ da cultura, respectivamente.

Os graus-dia relativos (GDr) que foram associados a uma escala relativa de estádios fenológicos (índice fenológico, $\mathrm{Fr}$ ) de 0 a 1 ( 0 = Emergência; 1 = ponto de maturidade fisiológica) foram estimados conforme a equação 6 :

$$
G D r=\frac{G D_{i}}{G D_{p m f}}
$$

em que GDi refere-se ao número de graus-dia do i-ésimo dia após a emergência.

\section{RESULTADOS E DISCUSSÃO}

A introdução da cultura em certa região pode ser prevista utilizando a determinação do número de graus dia, fazendo-se uso das variações meteorológicas (temperatura), associadas às observações fenológicas das plantas.

$\mathrm{Na}$ TABELA 2 e na TABELA 3 são apresentados os graus-dia necessários para que os três híbrido, nas três épocas de semeadura, expressassem os seus diferentes estádios fenológicos.

$\mathrm{Na}$ época 1, o período entre a emergência das plântulas e o estádio fenológico caracterizado com a emissão de 12 folhas (estádio 3) foi semelhante nos três híbridos em termos de dias após a emergência e grausdia. Por outro lado, os três híbridos, tanto na época 2 quanto na época 3 , começaram a diferir em termos de desenvolvimento a partir do estádio caracterizado com a emissão de 4 folhas (estádio 2). No entanto, os três híbridos nas três épocas de semeadura apresentaram maiores diferenças no estádio caracterizado com a emissão do pendão (estádio 4), sendo mais semelhantes, em termos de unidades térmicas para uma mesma época, os híbridos I e III.

Os graus-dia necessários para atingir o estádio fenológico caracterizado com o início do florescimento (estádio 5) foram menores na época 3 e maiores na época 2 para os três híbridos refletindo-se no rendimento da cultura, conforme mostrado na Figura 1.

Observa-se na Figura 1 que o rendimento de grãos diminui à medida que a temperatura média durante a fase vegetativa aumenta. Isso ocorreu devido a época de semeadura estar restrita ao início do período de chuva (agricultura de sequeiro). Por esse motivo, não se observaram respostas crescentes de rendimento com o aumento da temperatura. Também, pode-se observar que sequeiro com boa distribuição de chuva durante o ciclo da cultura).

Observa-se na TABELA 3 que nas três épocas de semeadura o híbrido I foi o primeiro a atingir o ponto de maturidade fisiológica, verificando-se a sua precocidade, conforme as características obtidas da Divisão de Sementes Híbridas da Cargill Brasil. Em trabalhos para determinação de épocas de semeadura, realizados por 
TABELA 2 - Eventos caracterizados nos três híbridos e nas três épocas, desde a semeadura até o final da fase de crescimento vegetativo (início do florescimento).

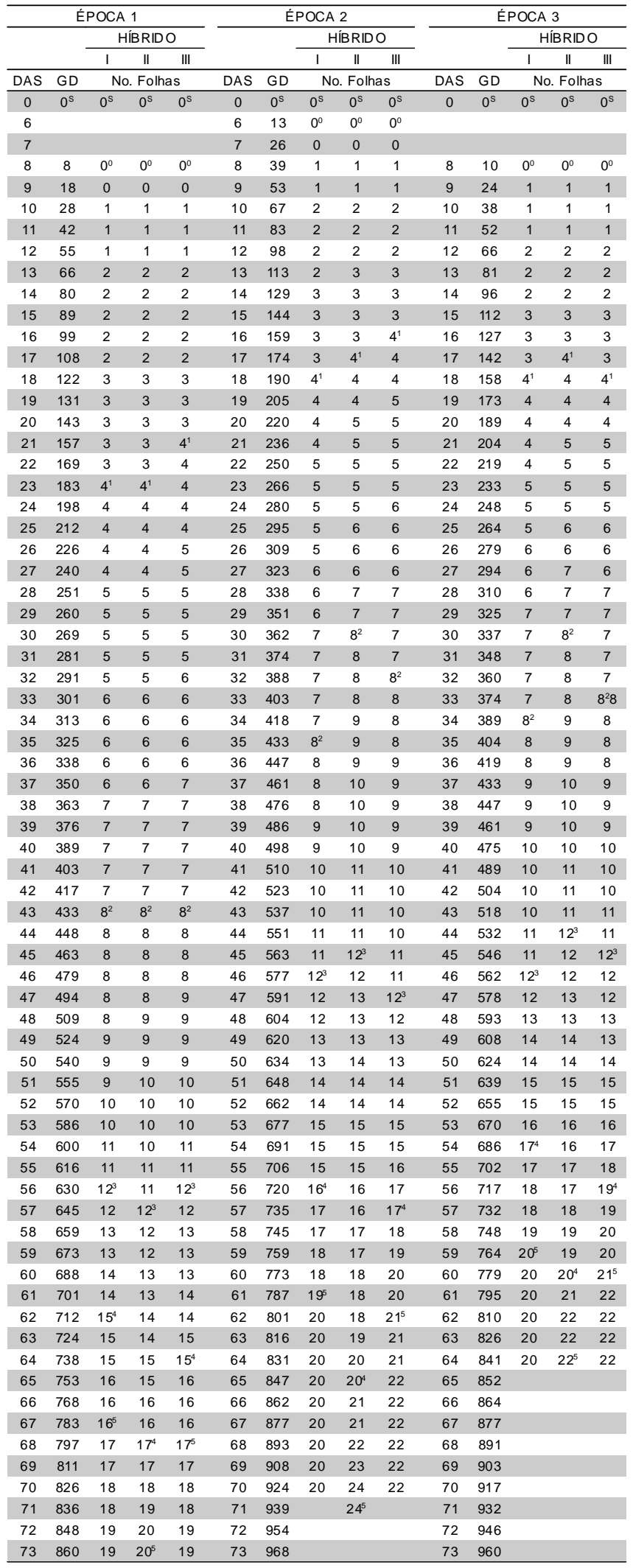

DAS = dias após a semeadura; GD = graus-dia; ${ }^{\mathrm{s}}$ Semeadura . Estádio fenológico: ${ }^{0}$ Emergência; ${ }^{1} 4$ folhas; ${ }^{2} 8$ folhas; ${ }^{3} 12$ folhas; ${ }^{4}$ emissão do pendão; ${ }^{5}$ início do florescimento.
TABELA 3 - Eventos caracterizados nos três híbridos e nas três épocas, desde a fase de florescimento até a colheita.

\begin{tabular}{|c|c|c|c|c|c|c|c|c|c|c|c|c|}
\hline \multicolumn{5}{|c|}{ ÉPOCA 1} & \multicolumn{4}{|c|}{ ÉPOCA 2} & \multicolumn{4}{|c|}{ ÉPOCA 3} \\
\hline & & \multicolumn{3}{|c|}{ HÍBRIDO } & & \multicolumn{3}{|c|}{ HÍBRIDO } & & \multicolumn{3}{|c|}{ HíBRIDO } \\
\hline & & I & II & III & & 1 & II & IIII & & 1 & II & III \\
\hline DAS & GD & No. & Folha & & DAS GD & No. & Folha & & DAS GD & No. & Folhe & \\
\hline 59 & 673 & & & & $59 \quad 759$ & & & & $59 \quad 764$ & $20^{5}$ & 19 & 20 \\
\hline 60 & 688 & & & & $60 \quad 773$ & & & & $60 \quad 779$ & 20 & 20 & $21^{5}$ \\
\hline 61 & 701 & & & & $61 \quad 787$ & $19^{5}$ & 18 & 20 & 61795 & & & \\
\hline 62 & 712 & & & & 62801 & 20 & 18 & $21^{5}$ & 62810 & & & \\
\hline 64 & 738 & & & & $64 \quad 831$ & 20 & 20 & 21 & $64 \quad 841$ & 20 & $22^{5}$ & 22 \\
\hline 66 & 768 & 16 & 16 & 16 & $66 \quad 862$ & 20 & 21 & 22 & $66 \quad 864$ & & & \\
\hline 67 & 783 & $16^{5}$ & 16 & 16 & $67 \quad 877$ & 20 & 21 & 22 & $67 \quad 877$ & & & \\
\hline 68 & 797 & 17 & 17 & $17^{5}$ & $68 \quad 893$ & 20 & 22 & 22 & $\begin{array}{ll}68 & 891\end{array}$ & & & \\
\hline 70 & 826 & 18 & 18 & 18 & $70 \quad 924$ & 20 & 24 & 22 & $\begin{array}{ll}70 & 917\end{array}$ & $83^{6}$ & & \\
\hline 71 & 836 & 18 & 19 & 18 & 71939 & & $24^{5}$ & & 71932 & & & \\
\hline 72 & 848 & 19 & 20 & 19 & $72 \quad 954$ & & & & 72946 & & & $83^{6}$ \\
\hline 73 & 860 & 19 & $20^{5}$ & 19 & $73 \quad 968$ & & & & 73960 & & & \\
\hline 75 & 887 & & & & $75 \quad 999$ & $80^{6}$ & & $80^{6}$ & 75989 & & & \\
\hline 78 & 927 & 19 & 20 & 19 & 781045 & 20 & 24 & 22 & 781035 & & & \\
\hline 79 & 941 & & & & 791060 & & & & 791051 & & $81^{6}$ & \\
\hline 80 & 954 & $80^{6}$ & & & 801072 & & & & 801067 & & & \\
\hline 81 & 970 & & & & 811083 & & & & 811083 & $60^{7}$ & & \\
\hline 82 & 984 & & & & 821095 & & & & 821099 & & & \\
\hline 83 & 998 & & & $83^{6}$ & 831109 & & $80^{6}$ & & 831115 & & & \\
\hline 84 & 1012 & & & & 841124 & & & & 841130 & & & $59^{7}$ \\
\hline 85 & 1027 & & & & 851139 & 57 & & & 851145 & & & \\
\hline 87 & 1056 & & & & 871168 & & & $56^{7}$ & 871176 & & & \\
\hline 88 & 1070 & $60^{7}$ & & & 881182 & & & & 881190 & & & \\
\hline 89 & 1085 & & & & 891196 & & & & 891206 & & $58^{7}$ & \\
\hline 90 & 1095 & & $83^{6}$ & & 901210 & & & & 901221 & $47^{8}$ & & \\
\hline 93 & 1137 & & & & 931253 & & $56^{7}$ & & 931266 & & & $46^{8}$ \\
\hline 94 & 1151 & & & $60^{7}$ & 941267 & & & & 941281 & & & \\
\hline 95 & 1166 & & & & 951281 & $45^{8}$ & & & 951296 & & & \\
\hline 97 & 1197 & $45^{8}$ & & & 971313 & & & $44^{8}$ & 971321 & & & \\
\hline 98 & 1212 & & & & 981328 & & & & 981332 & & $45^{8}$ & \\
\hline 100 & 1243 & & & & 1001359 & & & & 1001359 & & & \\
\hline 101 & 1258 & & $54^{7}$ & & 1011374 & & & & 1011373 & $36^{9}$ & & \\
\hline 102 & 1274 & & & & 1021390 & & & & 1021388 & & & \\
\hline 103 & 1289 & & & $45^{8}$ & 1031405 & & & & 1031402 & & & \\
\hline 104 & 1304 & & & & 1041421 & & $45^{8}$ & & 1041418 & & & $38^{9}$ \\
\hline 106 & 1333 & & & & 1061452 & $35^{9}$ & & & 1061448 & & & \\
\hline 108 & 1364 & & & & 1081483 & & & & 1081473 & & & \\
\hline 109 & 1379 & $35^{9}$ & $44^{8}$ & & 1091499 & & & $35^{9}$ & 1091487 & & & \\
\hline 110 & 1395 & & & & 1101514 & & & & 1101501 & & $36^{9}$ & \\
\hline 111 & 1410 & & & & 1111530 & & & & 1111516 & $33^{10}$ & & \\
\hline 113 & 1433 & & & $37^{9}$ & 1131561 & $33^{10}$ & & & 1131546 & & & \\
\hline 116 & 1474 & & & & 1161599 & & $37^{9}$ & & 1161576 & & & \\
\hline 117 & 1489 & & & & 1171612 & & & & 1171585 & & & $30^{10}$ \\
\hline 118 & 1504 & $31^{10}$ & & & 1181626 & & & & 1181596 & & & \\
\hline 119 & 1518 & & $39^{9}$ & & 1191638 & & & $30^{10}$ & 1191608 & & & \\
\hline 121 & 1546 & & & & 1211667 & & & & 1211633 & $23^{\mathrm{C}}$ & & \\
\hline 123 & 1574 & & & & 1231695 & & & & 1231662 & & & \\
\hline 124 & 1589 & & & $30^{10}$ & 1241709 & & & & 1241677 & & & \\
\hline 126 & 1617 & & & & 1261739 & & & & 1261707 & & $28^{10}$ & \\
\hline 127 & 1631 & & & & 1271755 & & & & 127 & & & $23^{\mathrm{C}}$ \\
\hline 130 & 1678 & & & & 1301802 & & $29^{10}$ & & 130 & & & \\
\hline 131 & 1693 & $23^{c}$ & & & 131 & & & & 131 & & & \\
\hline 133 & 1724 & & & $22^{\mathrm{C}}$ & 133 & $22^{c}$ & & & 133 & & & \\
\hline 134 & 1740 & & $29^{10}$ & & 134 & & & $22^{\mathrm{C}}$ & 134 & & & \\
\hline 139 & & & & & 139 & & & & 139 & & $19^{c}$ & \\
\hline 142 & & & & & 142 & & $20^{c}$ & & & & & \\
\hline
\end{tabular}

DAS = dias após a semeadura; GD = graus-dia. Estádio fenológico: ${ }^{5}$ florescimento; em \% de conteúdo de água: ${ }^{6}$ grão leitoso; ${ }^{7}$ grão pastoso; ${ }^{8}$ grão farináceo; ${ }^{9}$ grão duro e ${ }^{10}$ ponto de maturidade fisiológica. ${ }^{\mathrm{C}}$ colheita. 
Brunini et al. (1994), o mesmo híbrido apresenta-se mais precoce em relação a outras cultivares estudadas.

Comparando as três épocas de semeadura, observa-se, na TABELA 2 e na TABELA 3 que a redução do ciclo da cultura, desde a semeadura até o ponto de maturidade fisiológica, foi de 7 dias para os híbridos I e III e de 8 dias para o híbrido II.

A maior duração do ciclo apresentou-se no híbrido II na época 1 (1740 GD). Percebe-se ainda que a medida que a semeadura é retardada, ocorre uma redução na

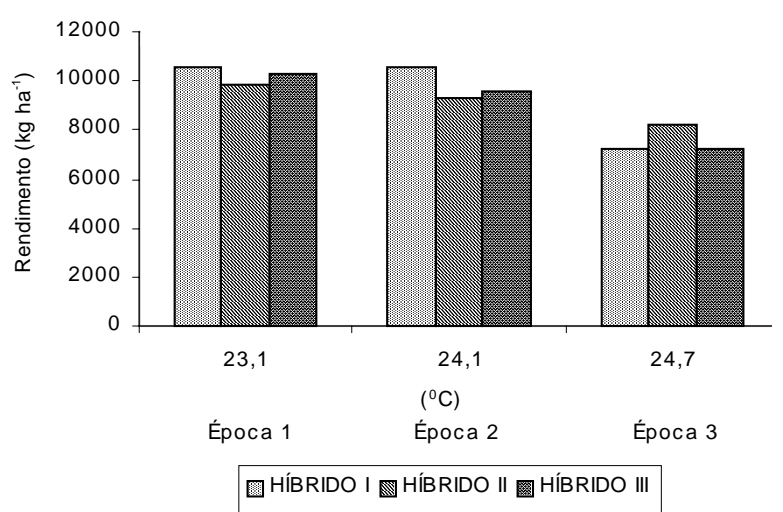

Figura 1 - Variação do rendimento médio de grãos em função da temperatura média na fase vegetativa da cultura do milho nas três épocas de semeadura. duração do ciclo por causa do encurtamento da fase vegetativa com leve incremento dos graus-dia na época Il para os três híbridos. Para um mesmo híbrido, a duração da fase reprodutiva foi similar nas três épocas de semeadura.

A caracterização fenológica dos híbridos permitiu evidenciar a relação funcional entre fenologia e graus-dia na cultura do milho. Na Figura 2 e na Figura 3 apresentase a relação entre a fenologia e os graus dia em termos relativos. Na primeira das figuras pode-se observar uma relação funcional linear das referidas variáveis para cada híbrido nas três épocas de semeadura. Sendo assim, generalizou-se essa relação por material genético (Figura $3 a, b$ e c) e depois, para a cultura do milho (Figura 3d).

Observa-se na TABELA 4 que o híbrido I nas três épocas apresentou número de fileiras superior em relação aos híbridos II e III. Os híbridos precoces mostraram redução no número de grãos com o atraso da semeadura, o que coincide com os resultados encontrados por Noldin e Mundstock (1988).

$\mathrm{Na}$ TABELA 5 são apresentados os resultados referentes ao número médio de grãos por espiga. $O$ número de grãos, assim como a massa média do grão, decresceu a medida que a semeadura foi atrasada.

O maior número de grãos por espiga observouse no híbrido III na época 1 e no menor no híbrido I na
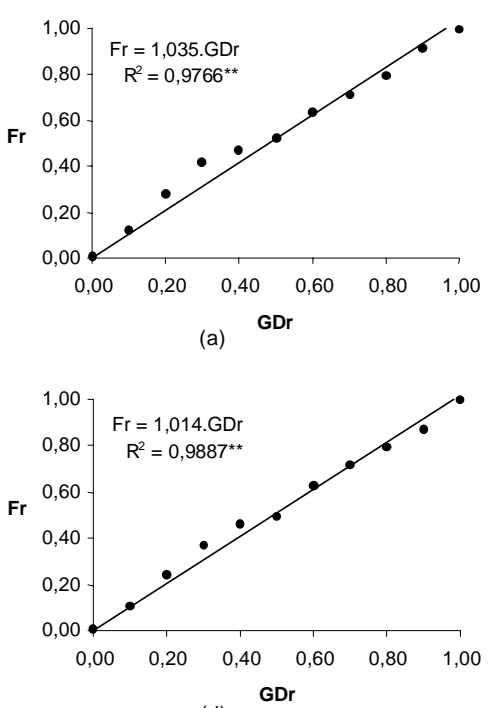

(d)

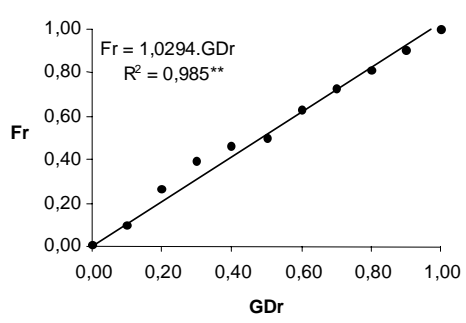

(g)

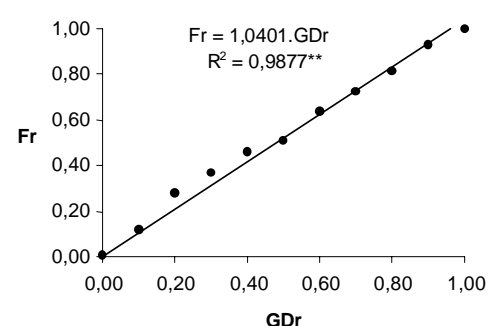

(b)

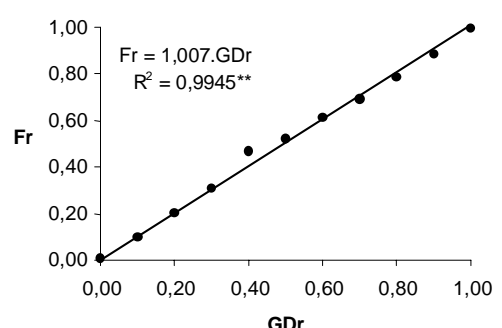

(e) GDr

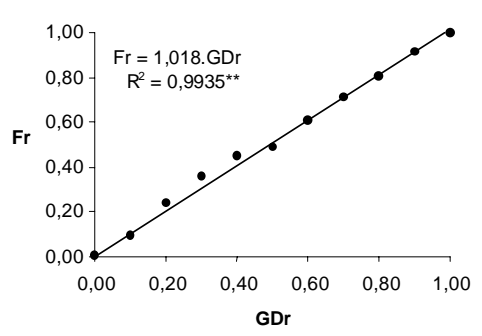

(h)

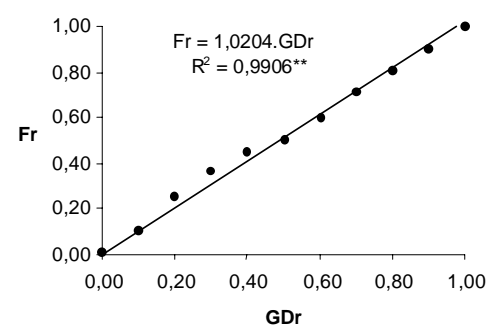

(c)
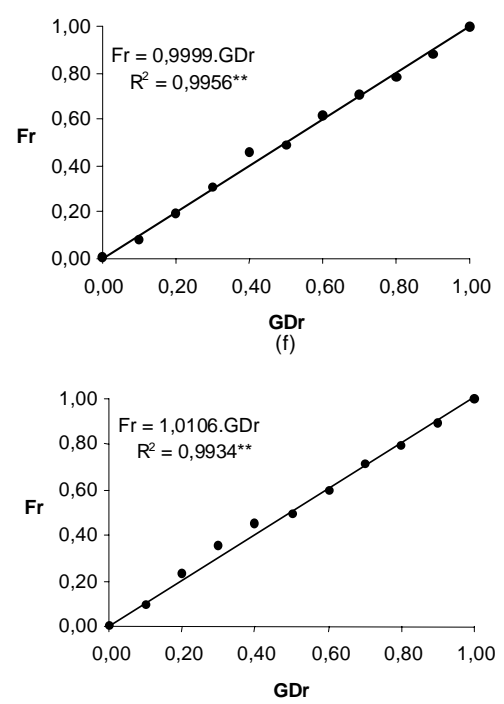

(i)

Figura 2 - Relação entre graus-dia e fenologia da cultura em termos relativos. a, b, c: híbrido I nas épocas 1 , 2 e 3 respectivamente; d, e, f: híbrido II nas épocas 1, 2 e 3 respectivamente; $g, h$, i: híbrido III nas épocas 1,2 e 3 respectivamente. (Significativo a $1 \%$ de $\left.\mathrm{R}_{9 ; 0,01}^{2}=0,54\right)$. 


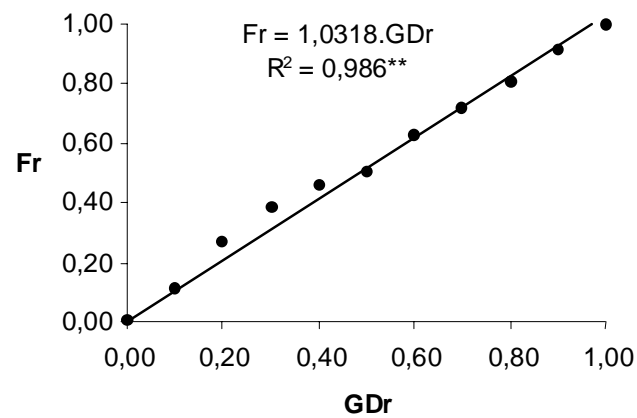

(a)

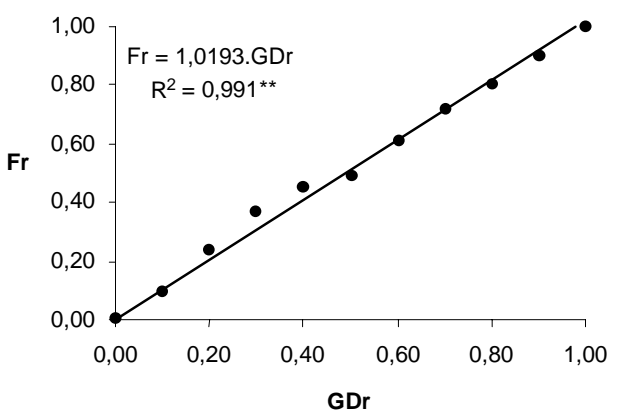

(c)

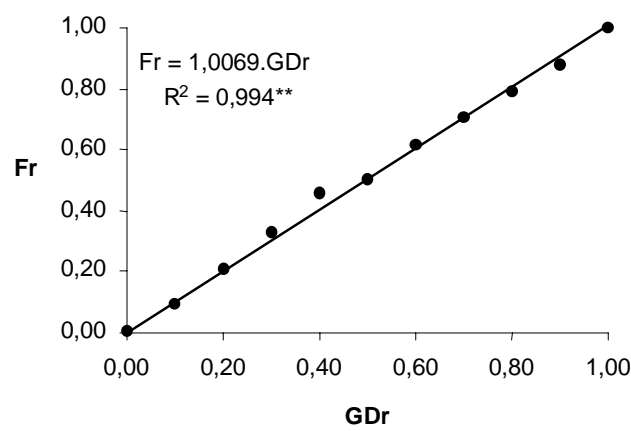

(b)

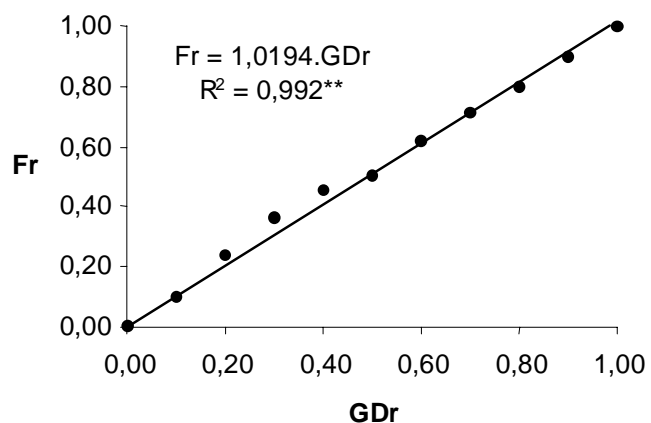

(d)

Figura 3 - Relação entre o índice de fenologia e número relativo de graus-dia nas três épocas de semeadura referente ao híbrido I (a), híbrido II (b), híbrido III (c) e cultura de milho (d) (média relativa dos três híbridos). (Significativo ao nível de 1\% de probabilidade: $\left.R_{9 ; 0,01}^{2}=0,54\right)$.

TABELA 4 - Número médio de fileiras $x$ número médio de grãos por fileira na espiga referente aos híbridos utilizados nas diferentes épocas de semeadura.

\begin{tabular}{cccc}
\hline \multirow{2}{*}{ Época } & \multicolumn{3}{c}{ Hîbrido } \\
\cline { 2 - 4 } & $\mathrm{I}$ & $\mathrm{I}$ & $\mathrm{II}$ \\
\hline \multirow{2}{*}{1} & $15,03 \times 34,18$ & $14,40 \times 37,80$ & $14,40 \times 40,03$ \\
& $(10,0 \times 12,0)$ & $(8,4 \times 10,4)$ & $(6,7 \times 9,1)$ \\
2 & $16,11 \times 33,14$ & $14,44 \times 36,81$ & $14,27 \times 38,53$ \\
& $(10,7 \times 10,0)$ & $(11,0 \times 8,0)$ & $(8,0 \times 6,9)$ \\
3 & $15,45 \times 28,60$ & $13,88 \times 36,12$ & $13,78 \times 3285$ \\
\multirow{2}{*}{ Média } & $(10,5 \times 13,7)$ & $(9,1 \times 6,0)$ & $(12,3 \times 14,0)$ \\
\hline
\end{tabular}

Valores entre parênteses referem-se ao coeficiente de variação (CV,

$\%)$ do número médio de fileiras e número médio de grãos por fileira.

época 3, entretanto o híbrido II mostrou maior estabilidade entre épocas em relação a este componente do rendimento. A massa média por unidade de grão decresce para todos os híbridos a medida que se retarda a época de semeadura.

O rendimento nas épocas 1 e 2 foi semelhante, ocorrendo na época 3 diminuição acentuada para os híbridos I e III. O híbrido II apresentou menor redução no rendimento na terceira época de semeadura, devido o mesmo possuir maior soma calórica.

Observa-se na Figura 1 que o rendimento de grãos diminui à medida que a temperatura média durante a fase vegetativa aumenta. Também, material com maior soma calórica (híbrido II) é mais recomendado para época de maior temperatura média.
TABELA 5 - Número médio de grãos por espiga ( $\mathrm{Ne}$ ), massa de 100 grãos (M100) e rendimento.

\begin{tabular}{|c|c|c|c|c|c|c|c|c|c|}
\hline \multirow[t]{2}{*}{ Época } & \multicolumn{3}{|c|}{$\mathrm{Ne}$} & \multicolumn{3}{|c|}{ M100 } & \multicolumn{3}{|c|}{ Rendimento } \\
\hline & I & $\|$ & III & I & $\|$ & III & I & $\|$ & III \\
\hline & grão & s esp & iga $^{-1}$ & $g(1$ & 00grã & áos) $)^{-1}$ & & $\mathrm{~kg} \mathrm{ha}^{-1}$ & \\
\hline 1 & 514 & 544 & 576 & 34,2 & 36,2 & 35,6 & 10.553 & 9.859 & 10.258 \\
\hline 2 & 534 & 532 & 550 & 33,0 & 35,1 & 34,8 & 10.570 & 9.321 & 9.551 \\
\hline 3 & 442 & 501 & 453 & 27,2 & 32,8 & 31,9 & 7.218 & 8.215 & 7.210 \\
\hline Média & 497 & 526 & 526 & 31,5 & 34,7 & 34,0 & 9.447 & 9.132 & 9.007 \\
\hline
\end{tabular}

\section{CONCLUSÃO}

Há uma temperatura média do ar correspondente ao máximo rendimento de grãos. Os estádios fenológicos da cultura podem ser previstos por meio do conhecimento prévio da série histórica de temperatura da localidade e da soma calórica requerida pelo material genético para atingir o ponto de maturidade fisiológica.

\section{REFERÊNCIAS BIBLIOGRÁFICAS}

BERLATO, M.A.; MATZENAUER, R.; SUTILI, V.R. Relação entre temperatura e o aparecimento de fases fenológicas do milho (Zea mays L.). Agronomia Sulriograndense, v.20, p.111-132, 1984.

BRASIL. Ministério da Agricultura. Regras para análise de sementes. Brasília, 1992. 365p. 
BRUNINI, O. Probabilidade de cultivo do milho "safrinha" no Estado de São Paulo. In: SEMINÁRIO SOBRE A CULTURA DO MILHO SAFRINHA, 4., Assis, 1997. Anais. s.I.:s.ed., 1997. p.37-55.

BRUNINI, O.; ALFONSI, R.R.; PAES DE CAMARGO, M.B. Efeito dos elementos climáticos no desenvolvimento da cultura de milho. In: SIMPÓSIO SOBRE PRODUTIVIDADE DO MILHO. Londrina, 1983. Anais. Londrina: IAPAR/EMBRAPA, CNPMS, 1983. p.21-40.

BRUNINI, O.; BORTOLETTO, N.; CASTRO, J.L.; SORD, G.; DUARTE, A.P.; GALLO, P.B.; Kanthack, R.A.D.; LANDELL, M.; MEREGE, W.H.; MARTINS, A.L.M.; PEREIRA, J.C.V.N.; SAWAZAKI, E. Épocas de plantio para o cultivo do milho "sasfrinha" no Estado de São Paulo. In: SEMINÁRIO SOBRE A CULTURA DO MILHO SAFRINHA, 3., Assis, 1995. Resumos. Campinas, IAC, CDV, 1995. p.67.

COSTA, A.F.S. da. Influência das condições climáticas no crescimento e desenvolvimento de plantas de milho (Zea mays L.), avaliadas em diferentes épocas de plantio. Viçosa, 1994. 109p. Tese (Doutorado) - Universidade Federal de Viçosa.

FANCELLI, A.L.; DOURADO-NETO, D. Milho: ecofisiologia e rendimento. In: TECNOLOGIA DA PRODUÇÃO DE MILHO, 1., Piracicaba, 1997. Trabalhos Apresentados. Piracicaba, 1997. p.157-170.

GARCIA, B.I.L. Determinação de temperatura-base e influência de variáveis climáticas na duração do ciclo e na produção do milho (Zea mays L.). Piracicaba, 1993. 81p. Dissertação (Mestrado) - Escola Superior de Agricultura "Luiz de Queiroz", Universidade de São Paulo.

KÖPPEN, W. Climatologia: con un estudio de los climas de la tierra. México: Fondo de Cultura Económica, 1948. 478p.

LIMA, T.S.O.; MOURA, G.M.; BRITO, P.F.A.; LODI, N.V. Efeito de épocas de plantio na produção de cultivares de milho. Rio Branco: EMBRAPA,UEPAE, 1980. 4p. (Comunicado Técnico, 20).
MUNDSTOCK, C.M. Ciclo de crescimento e desenvolvimento de seis cultivares de milho em quatro épocas de semeadura. In: REUNIÃO BRASILEIRA DO MILHO, 8., Porto Alegre, 1970. Anais. Porto Alegre: Secretaria de Estado dos Negócios da Agricultura, 1970. p.18-29.

NOLDIN, J.A.; MUNDSTOCK, C.M. Rendimento de grãos e componentes de rendimento de três cultivares de milho em duas épocas de semeadura. Pesquisa Agropecuária Brasileira, v.23, p.615-620, 1988.

OLIVEIRA, M.D.X. Comportamento da cultura do milho (Zea mays L.) em diferentes épocas de semeadura nas regiões centro e norte de Mato Grosso do Sul. Lavras, 1990. 90p. Dissertação (Mestrado) - Escola Superior de Agricultura de Lavras.

PACHECO, C.A.P. Considerações sobre época de semeadura para milho em Dourados, MS. Dourados: EMBRAPA,UEPAE, 1982. 9p. (Comunicado Técnico, 10).

PRETT, S. Comparison of seasonal thermal indices for measurement of corn maturity in a prairie environment. Canadian Journal of Plant Science, v.72, p.1157-1162, 1992.

RAIJ, B. van.; CANTARELLA, H.; QUAGGIO, J.A.; FURLANI, A.M.C. Recomendações de adubação e calagem para o Estado de São Paulo. 2.ed. Campinas: IAC, 1996. 285p. (Boletim Técnico, 100).

SOUZA, F.R.S. de. Estabilidade de cultivares de milho (Zea mays L.) em diferentes épocas e locais de plantio de Minas Gerais. Lavras, 1989. 80p. Dissertação (Mestrado) - Escola Superior de Agricultura de Lavras.

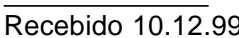

